\title{
Social validation: a motivational theory of doping in an online bodybuilding community
}

\section{Brendan Hutchinson, Stephen Moston \& Terry Engelberg}

To cite this article: Brendan Hutchinson, Stephen Moston \& Terry Engelberg (2015): Social validation: a motivational theory of doping in an online bodybuilding community, Sport in Society, DOI: 10.1080/17430437.2015.1096245

To link to this article: http://dx.doi.org/10.1080/17430437.2015.1096245

曲 Published online: 29 Oct 2015.

Submit your article to this journal $\lceil\pi$

山 Article views: 52

View related articles $₫$

View Crossmark data ¿ 


\title{
Social validation: a motivational theory of doping in an online bodybuilding community
}

\author{
Brendan Hutchinson ${ }^{a}$, Stephen Moston ${ }^{a, b}$ and Terry Engelberg ${ }^{c, d}$

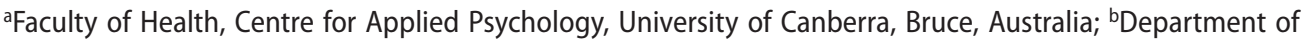 \\ Psychology, College of Healthcare Sciences, James Cook University, Townsville, Australia; 'Department of \\ Tourism, Sport and Hotel Management, Griffith University, Gold Coast, Australia; 'dSport and Exercise Science, \\ College of Healthcare Sciences, James Cook University, Cairns, Australia
}

\begin{abstract}
Doping research has predominantly been framed through an ethical lens, implicitly restricted to the realms of elite sport. Despite increasing anecdotal evidence of growing prevalence rates amongst recreational athletes, such as bodybuilders, these populations have largely been neglected within psychological research. This study aims to develop a theoretical framework relevant to these athletes. Data were collected over a five-month period from an online community forum dedicated to recreational bodybuilders. Purposive sampling was used to gather 118 webpages of doping-related discussion, which were qualitatively analysed using grounded theory applying Strauss's coding paradigm. Inductive categories were integrated into a motivational framework that related recreational doping to social validation. Categories included the online community's rite of passage, normative-inferences that facilitated doping, and deterrence factors related to fear of perceived health risks. Findings demonstrate that, for recreational bodybuilders, psychosocial processes are significantly related to doping motives, and that health factors are primary doping deterrents.
\end{abstract}

From the time doping began to diffuse into professional sport throughout the 1960s, researchers and policy-makers alike have had considerable difficulty in establishing how to conceptualize doping (Verroken 2000). According to the World Anti-Doping Agency (WADA 2013), doping can be characterized by the use of any method that enhances performance, surpasses the realm of fair play and involves a health risk to the individual user (Sjöqvist, Garle, and Rane 2008). This definition effectively illustrates the ethical and medical grounds by which anti-doping policy has been justified. Psychological research has followed by framing doping as an issue of ethical misconduct, or an issue of health concern, with the former emerging as the dominant approach.

In framing doping as an issue of ethical wrongdoing, the psychological literature was initially driven by anti-doping policy, and was concerned with exploring athlete attitudes

CONTACT Brendan Hutchinson u3052809@uni.canberra.edu.au

This article was originally published with errors. This version has been corrected. Please see Corrigendum (http://dx.doi.org/ 10.1080/17430437.2015.1117247)

(c) 2015 Taylor \& Francis 
toward doping (Alaranta et al. 2006; Kisaalita and Robinson 2014), and public perceptions of doping (Engelberg, Moston, and Skinner 2012; Stamm et al. 2008). Research in this domain was, for many years, heavily criticized for lacking a specified conceptual framework (Backhouse et al. 2007; Gucciardi, Jalleh, and Donovan 2011). An early attempt at providing such a framework came from the sports drugs control (Donovan et al. 2002), which proposed a web of interrelated mechanisms that largely related doping to other immoral behaviours such as illicit drug use. While theoretically stimulating, the model's ambitious nature proved overly difficult to apply, and the model received little empirical support as a result (Gucciardi et al. 2011; Jalleh, Donovan, and Jobling 2014).

Research thus deviated from the development of a doping-specific framework and sought a theory of moral behaviour, in turn pursuing an understanding of doping from a perspective of ethical misconduct. Researchers adopted the theory of moral disengagement (Bandura et al. 1996), which proposes a framework of eight mechanisms (displacement of responsibility, diffusion of responsibility, advantageous comparison, distortion of consequences, moral justification, euphemistic labelling, attribution of blame and dehumanization) that enable the justification of immoral behaviour (for a full elaboration of the model, refer to Bandura et al. 1996). Briefly, the theory proposes that these mechanisms facilitate unethical behaviour through selective inhibition of internal standards. A series of studies by Lucidi and colleagues (Lucidi et al. 2004, 2008; Lucidi, Zelli, and Mallia 2013; Zelli, Mallia, and Lucidi 2010) examined moral disengagement (Bandura et al. 1996) amongst large samples of Italian adolescents. Reported findings were generally supportive of the theory and its central premise that an inhibition of internal standards facilitated doping.

A large portion of the literature has thus focused toward examining doping through a lens of ethical transgression restricted to the realms of professional sport (Kayser, Mauron, and Miah 2007). Researchers have primarily sampled elite-athletes from a variety of sporting disciplines (Barkoukis et al. 2011, 2013; Lazuras et al. 2010), despite a body of evidence now suggesting that athlete psychological indices and doping occurrence rates vary based upon one's level of profession (Backhouse et al. 2007; Ehrnborg and Rosén 2009; MorenteSánchez and Zabala 2013; Pedersen 2010) and sporting discipline (Lazuras et al. 2010; Smith et al. 2010). The concern is exacerbated by recent prevalence estimates (Sagoe and Andreassen 2014), which illustrate that doping is now most common among recreational (non-competitive) athletes.

Consequently, there is a converging view that doping has diffused from professional to recreational sport (Diehl et al. 2012; Kanayama, Hudson, and Pope Jr. 2008; Moston, Engelberg, and Skinner 2014), and that theoretical generalizations of current research outcomes to broader populations of recreational athletes may be preemptive (Morente-Sánchez and Zabala 2013). Given that these athletes have limited financial and competitive incentives (Backhouse et al. 2007; Ehrnborg and Rosén 2009), and few ethical deterrents, healthfocused research may be necessary for these athletes. Indeed, the small body of health-related research has deviated from the ethical literature, and has alternatively recognized doping as a pathological behavioural outcome of severe disturbances in body image (Keane 2005), specifically within recreational bodybuilding athletes (Blouin and Goldfield 1995; Goldfield 2009).

The most common doping practice within these sporting disciplines has reportedly been performance-enhancing drugs (PEDs), particularly anabolic steroids (Holt, ErotokritouMulligan, and Sönksen 2009; Kanayama, Hudson, and Pope Jr. 2008; Sagoe and Andreassen 
2014), which have additionally been demonstrated as the most frequent doping substance among the general public (Simon et al. 2006; Verroken 2000). Estimates of PED use in the USA alone are between 1 and 3 million (Sjöqvist, Garle, and Rane 2008). Further, the majority of doping health risks are reportedly the outcome of anabolic steroid use (Amsterdam, Opperhuizen, and Hartgens 2010). Research focusing on these athletes therefore may be necessary, not only to resolve the absence of theoretical and empirical progress in this area, but for the sake of public health.

These issues are further compounded by current methodologies in practice. Specifically, there is growing concern for the inherent social desirability within doping research (Petróczi 2007; Petróczi and Aidman 2009; Wiefferink et al. 2008). Social desirability is the tendency to respond in what is perceived to be the appropriate manner to avoid conviction or punishment (Lazuras et al. 2010). A growing body of evidence suggests that the social sanctions implicit to doping behaviour may fundamentally hinder current survey methodologies in practice (Backhouse et al. 2007).

To date, few studies have sought to measure social desirability, and little research has established the quality and degree to which it impacts upon doping measures. Nevertheless, researchers have begun seeking out alternative research methodologies. While some have proposed assessing doping behaviours using indirect measures (Barkoukis, Lazuras, and Tsorbatzoudis 2013) and through an increase in anonymity reassurance (Petróczi 2007), others have suggested deviation from quantitative methodology, and further emphasis on qualitative analysis, is essential (Andrews, Sudwell, and Sparkes 2005; Backhouse et al. 2007; Hauw and McNamee 2015; Pedersen 2010).

The small body of literature adopting a qualitative approach has largely remained exploratory, but has provided various insights into doping processes amongst recreational bodybuilding athletes. Research by Bilard (2011) explored motives linked to doping through analysing telephone conversations made to a French anti-doping phone help service between the years 2000 and 2005. From 358 calls, motives were revealed to be heavily associated with sporting discipline. While cyclists' motives involved performance and footballer motives included personal recreation, bodybuilders' motives were associated with the social norms of the sport. Thus, Bilard concluded that doping may be instigated in bodybuilding by social processes.

Correspondingly, ethnographic field work of various bodybuilding fitness centres by Monaghan (2002) demonstrated a fitness community embedded with attitudes and motives that facilitated doping-behavioural norms. Community members held beliefs that doping was a legitimate behaviour at any level of profession. Similarly, Andrews, Sudwell, and Sparkes (2005) conducted a case study of a bodybuilding fitness centre, discovering an environment that propagated doping through a social hierarchy contingent on physical ability and commitment to bodybuilding. Through its perceived prevalence, doping was legitimized and construed as a normative behaviour. Boardley and Grix (2014) interrelated this to Bandura et al.s (1996) moral disengagement mechanisms, in particular diffusion of responsibility (dispersing the responsibility of one's behaviour onto a social group), and displacement of responsibility (deeming an action as the result of social pressure). Through semi-structured interviews of 73 doping bodybuilders, major themes emerged concerning pressures to conform to the standards of doping bodybuilders within the community. Similar to Bilard (2011), Boardley and Grix proposed that social processes, specifically a diffusion and displacement of responsibility, were innate instigators of doping in the bodybuilding culture. 
More recently, Smith and Stewart (2012) conducted a virtual ethnography of an online bodybuilding community with the aim of exploring the online social structure in relation to recreational and competitive weight-lifters. Samples of online forum posts over a 36-month period illustrated similar outcomes to those of Andrews, Sudwell, and Sparkes (2005), where the online environment operated as a social hierarchy contingent on masculinity. Muscularity was highly sought and was associated with social status, and highly prevalent self-proclaimed doping practices were viewed as a necessary means to an end for weight-lifting-related goals. In addition, the community were heavily involved in information exchange related to doping, supporting research by Christiansen and Bojsen-Møller (2012) that online platforms function as a tool for the distribution of information for recreational doping.

Subsequently, given the limitations of traditional methodology, community-based online research is a viable option for the study of doping. Andrews, Sudwell, and Sparkes (2005) illustrated that becoming a member of the community was a difficult and necessary process to study the culture, but that through perceived trust and experience, they were able to uncover pertinent knowledge of otherwise concealed information, including how the community would avoid doping-related discussion with those perceived as external to the community. Similarly, Monaghan (2002) found the self-presentation of recreational bodybuilders was highly regulated toward particular audiences to present a moral self-image. For Smith and Stewart (2012), the anonymity assurance of online discussion encouraged expression of sensitive and concealed information, and the online structure enabled easy access to in-depth doping-related discussions.

\section{The present study}

The present study sought to utilize the online forum to establish a theory of doping amongst recreational bodybuilders. As a doping framework, moral disengagement (Bandura et al. 1996) has disregarded health-related factors that are paramount to a broader population of doping athletes. Thus, there remains a need for a theoretical framework of doping that focuses on understanding these factors and their relation to doping amongst recreational athletes. Specifically, bodybuilding athletes have been recognized as susceptible to pathological doping behaviour (Blouin and Goldfield 1995; Goldfield 2009), therefore understanding the inherent psychological factors amongst this population may be a necessary step in facilitating research toward a broader population of athletes. Given previous research outcomes (Andrews, Sudwell, and Sparkes 2005; Monaghan 2002; Smith and Stewart 2012), identifying explicit social processes is a necessary component of this goal. As the most prevalent method of doping in recreational bodybuilding is the use of PEDs (Holt, Erotokritou-Mulligan, and Sönksen 2009; Kanayama, Hudson, and Pope Jr. 2008; Simon et al. 2006; Verroken 2000), the current study sought to specifically understand PED use in the online community.

Smith and Stewart (2012) demonstrated that the online domain offers an innovative instrument for constructing and shaping cultural lifestyle. Thus, similar to their work (Smith and Stewart 2012), a window of postings made within a five-month period on an online sub-forum devoted to recreational bodybuilding discussion were qualitatively analysed. As the purpose of research was theory development, a constructivist grounded theory (Mills, Bonner, and Francis 2006) approach was adopted. The aim was therefore to provide a conceptually rich understanding of PED use amongst the online recreational bodybuilding community, specifically to generate hypotheses in relation to; the motives to engage in PED 
Table 1. Online research systematic selection criteria for site of data collection.

\begin{tabular}{|c|c|c|}
\hline Criteria & Definition & Goodness of fit \\
\hline Authoritativeness & Is the site moderated? & $\begin{array}{l}\text { Website forums are regularly moderated to en- } \\
\text { sure maintenance and standards are up-kept }\end{array}$ \\
\hline Trustworthiness & Does the site convey legitimate purpose? & $\begin{array}{l}\text { The main website functions as a nutritional store } \\
\text { and online-article publisher, which in turn gather } \\
\text { considerable traffic }\end{array}$ \\
\hline Up-to-date & The regularity by which pages are created & More than 100 threads are created daily \\
\hline Popularity & The extent of recognition and size of audience & $\begin{array}{l}\text { The forums have culminated over six million } \\
\text { threads and over } 100 \text { million posts in more than a } \\
10 \text {-year time period }\end{array}$ \\
\hline
\end{tabular}

Table 2. Sample of threads extracted for data analysis accompanied by number of users and posts.

\begin{tabular}{lcc}
\hline Thread title & \# of users in thread & \# of posts in thread \\
\hline Why not take dat dere celltech & 77 & 163 \\
I'm sick of natty lifting & 56 & 94 \\
That feel when you're natty but get accused of celltech & 50 & 64 \\
What is your reason for being natty & 49 & 72 \\
The only reason stopping me going on the JUICE & 16 & 21 \\
\hline
\end{tabular}

Note: See Table 3 for definitions of forum terminology.

use amongst the online recreational bodybuilding community; how the relation between health outcomes and PED use are interpreted by community members, and; the social processes within the community.

\section{Method}

\section{Participants}

Participation in discussions within the website's forum requires the creation of an individual avatar. These are used for identification between members of the online forum. A total of 1544 avatars were involved in the sampled discussions. The individual may choose to reveal or withhold personal attributes through their avatar that include geographical location, age, gender, height and weight. While Markham (2004a, 371) suggests that the increased control in self-presentation supports the legitimacy of the online-self, authenticity of demographic data must be cautioned due to the anonymity of online discussion (Smith and Stewart 2012). To achieve ethical integrity, this information was de-identified and withheld as per a 'maximum cloaking' strategy (Kozinets 2010, 164). This stance has been well corroborated (Kozinets 2010; Lipinski 2006) as to ensure no breach of privacy invasion during online archival research barring informed consent.

\section{Data collection}

A grounded theory (Strauss 1987) approach was undertaken within a social constructivist paradigm (Guba and Lincoln 1989), which asserts that reality is a social construction of the mind and hence is heavily influenced by context. It is therefore acknowledged that the research is situated within a particular sociocultural context and is limited in generalizability by the research design. The primary source of data was online forum 'threads. Threads are 
Table 3. Terminology used by the online community accompanied by their meanings.

\begin{tabular}{ll}
\hline Meanings & Terminology \\
\hline PEDs & Bike, bicycle, cycle, cell-tech, juice, ride, tech, vitamin t \\
PED use & Boost, cycling, juicing, the dark side, riding, touring, Tour de France, riding \\
PED user & Juicer, not-natty \\
PED user appearance & Juicy \\
Not using PEDs & Natural, natty \\
\hline
\end{tabular}

Note: Terminology includes variations of those listed.

strings of posts that are connected by a central theme. In this regard, threads are discussions, and the structure of an online forum allows for a unique archival collection of a community's discussion history. By entering a phrase into a search engine, it is possible to explore past discussions in full. This method of data collection was therefore considered pertinent given the study aim, and offered a unique and robust research design.

To determine the site for research, a selective sampling procedure (Strauss 1987) was employed in which theoretically relevant systematic criteria were used to guide data collection. Thus, the research site was chosen based upon Denscombe's $(2010,223)$ criteria for robust online research (see Table 1).

A total of 118 web pages consisting of 45 threads of data were downloaded from a specific sub-forum off the main website. This sub-forum was chosen for its high degree of traffic, primarily comprised of recreational bodybuilders, relative to other sub-forums. As suggested by Markham (2004b), no downloaded web pages of data were altered. The largest thread contained nine web pages of running discussion based around PED-related topics. Purposive sampling (Birks and Mills 2011) was undertaken in which thread titles were used as an indicator of relevance. If the thread title directly or indirectly suggested PED discussion, they were further inspected. If any reference to PED-related discussion was evident, the full thread was captured for analysis. A sample of four threads can be found in Table 2 .

Theoretical sampling (Strauss 1987), whereby additional data collection was determined on the basis of emergent theme verification, was undertaken using two methods: through observation of the sub-forum, and through the forums search engine function. Although this sampling procedure does not yield a random sample, it is considered essential for theoretical category development (Strauss and Corbin 1998). A total of three threads that originated outside the initial sub-forum were included in the data pool from accompanying database searches.

Explicit discussion of PEDs is banned on the website. To bypass moderation, forum members shared highly context adaptive terminology denoting PEDs, PED usage and similar themes. A list of phrases and their meanings can be found in Table 3. Definitions were developed pragmatically through examining online discussions for linguistic patterns. All definitions were cross-referenced with an independent researcher and two fitness professionals.

All quotes were presented verbatim with translations bracketed. While the American Psychological Association (2010) suggest signifying errors by use of ' [sic]', for ease of readability, this has been omitted in quotes due to the frequency of spelling, punctuation and grammatical errors. 


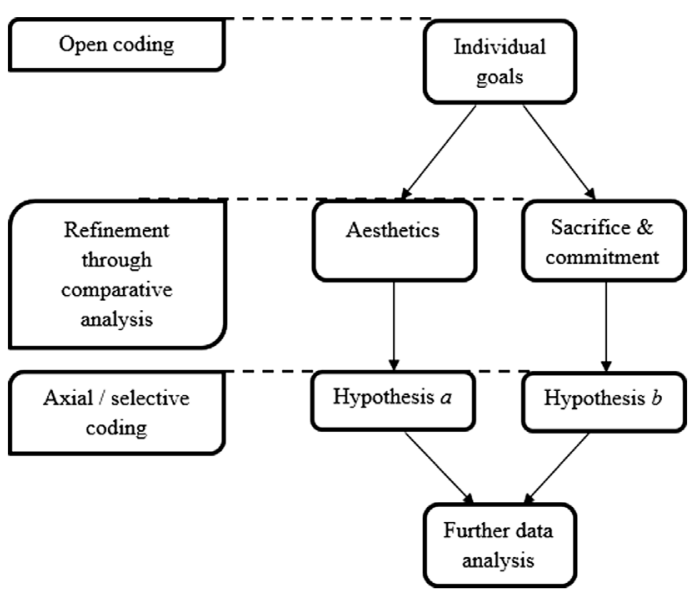

Figure 1. Coding extract within a particular thematic section, from open coding to selective coding. Hypothesis $a$ refers to utilizing one's appearance as a source of validation. Hypothesis $b$ refers to the implicit rite of passage process of the online community.

Table 4. Data coding: extract from axial and selective coding stage of data analysis.

\begin{tabular}{lll}
\hline Category & Sub-category & Example \\
\hline Validation & Cultural & $\begin{array}{l}\text { Everyone lifts to impress girls (or guys) to a certain degree. Anyone who says they lift } \\
\text { (aesthetically speaking) purely for themselves is lying } \\
\text { Been lifting natty for a long time and thought l'd weigh in. My pic is at the end of a cut } \\
\text { when I ate clean and trained hard for 4 months after building up a solid base to work } \\
\text { from for YEARS }\end{array}$ \\
Inhibitors & Group & $\begin{array}{l}\text { Don't want to mess up my hormones - don't want increased risk of health problems - } \\
\text { scared of injecting myself with sketchy substances } \\
\text { Iheard it was incredibly addicting ... the gains from it, and it sucks you into never want- } \\
\text { ing to come off again. Not sure I want to be stuck on the tech [PEDs] }\end{array}$ \\
\hline
\end{tabular}

Note: Categories were highlighted as axial codes, and then theoretically developed through sub-categories at the selective coding stage (Strauss 1987).

\section{Data analysis}

Coding occurred inductively to allow for theory to emerge (Silverman 2009) and followed Strauss's (1987) three stages of open coding, axial coding, and selective coding. Coding began with a line-by-line analysis of discussions (Strauss and Corbin 1998). Commencing with a microscopic coding strategy allows for a foundation to facilitate further coding efficiently and with maximal conceptual density (Strauss 1987). The constant comparative technique (Maykut and Morehouse 1994) was employed to ensure objective and precise conceptualization. This involved analysis and integration of negative cases (Strauss 1987). These procedures permitted theoretical verification through category refinement. Figure 1 illustrates an example of the coding procedure from open coding to hypotheses formulation.

Guided by Strauss's (1987) grounded theory coding paradigm, axial and selective coding occurred through hypothesis testing of central categories and their relationships to subcategories. This enabled conceptual density through consideration of conditions, 
consequences and interactions within and between categories (Strauss and Corbin 1998). Coding extracts of two categories and sub-categories from the axial and selective coding stage are illustrated in Table 4. To enhance reliability, an independent researcher coded 10\% of web pages. There were no outstanding disagreements between coders. All coding was maintained with an audit trail (Birks and Mills 2011) within Nvivo 10 (QSR International 2012).

Validation was defined as perceived social recognition for an individual's effort or achievement. Inhibitors were defined as factors that were considered sufficient to deter individuals from PED use.

\section{Procedure}

Because this research used publicly available archival data extracted from an observational standpoint (Kozinets 2010), no approval through an ethics committee was necessary prior to analysis. Data collection occurred within a five month period between March and July of 2014, and involved seeking out discussion of PEDs through observation of the sub-forum for relevant data. Data collection persevered until the amount of data collected was considered adequate for theoretical saturation (Strauss 1987). Saturation, in this instance, was defined as the point at which data collection no longer enriched the emerging theoretical construct. Data were collected by the first author who had no relationship with any forum participant.

\section{Results}

The online forum offered a rich source of data with regard to the research aims of understanding motivations toward PEDs, how individuals construe health outcomes, and the social processes within the community. A number of unexpected developments provided conceptually rich insight into the online group dynamics, and how these may expedite PED use. The recreational bodybuilding community functioned much like a social group, with colloquialisms shared among members, and members illustrating a desire for group cohesiveness.

A number of concepts emerged. The results will be discussed with regard to those most relevant to the research aims: the rite of passage process that framed the online community as a functioning group, the social processes that facilitated PED use (enablers), the motivating factors for individuals to use PEDs (drivers) and the factors that deterred individuals from PED use (inhibitors). The results will be structured and explored around these four major categories. A hypothesized conceptual model integrated all of these categories, with validation emerging as the core category (see Figure 2). All concepts that emerged were robust both in quality and in occurrence, in that they were developed from citations by a moderate number of members.

\section{A rite of passage}

Demonstrating sacrifice, discipline and commitment to bodybuilding was of high value to the online community. Personification of these characteristics was a well recognized yet implicit milestone that facilitated admiration and respect by other members. Given 


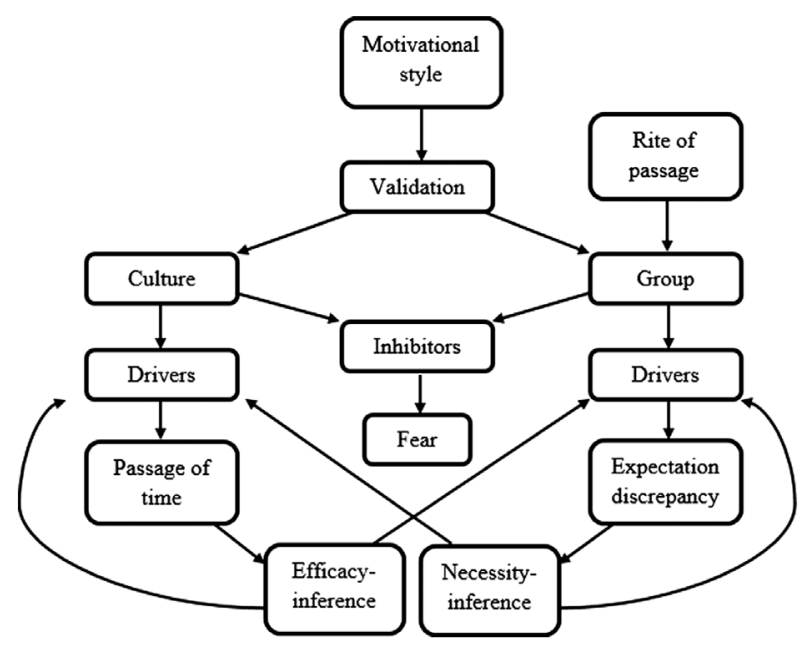

Figure 2. Hypothesized conditional and interactional relationships between conceptual categories that emerged during data analysis.

the perceived social value of these ideals, individuals showed aspiration to embody them. Equally, deviating from these traits was typically met with heavy scorn by the community. This multifaceted phenomenon resembled a rite of passage process, whereby individuals were accepted as members of the community, or were ostracized as non-members. A rite of passage is a group or cultural ritual that marks a change in an individual's social status (Gennep 1960), and can be indicative of the values and beliefs that are important to a society or group. In this circumstance, the rite of passage process was highly symbolic of the online community as a functioning social group, and underscored many of the psychological processes within the community, both with and without regard to PED use (see Figure 2). The results to follow will exemplify these processes and their relation with the rite of passage.

\section{Enablers}

Several social processes unfolded during analysis that may function to enable PED use in the community. These enablers were distinct heuristic assumptions that proliferated through social discussion. Two explicit inferences arose, the efficacy-inference and necessity-inference.

\section{Efficacy-inference}

This inference related to the perceived effectiveness of PEDs. Community members would allude to PEDs as embedded with properties that could allow any individual to attain an exceptional physique with their use, regardless of other factors such as individual ability:

I'd like to be the one to say cell-tech [PEDs] isn't a magic pill/injection that will transform you from 'do you even lift?' to 'holy fuark' in 12 months ... but I can't. I've had plenty of friends that started juicing [using PEDs] way too early (i.e. after 6 months of lifting), but that exploded to a size where you'd think they'd been lifting for at least $4-5$ years natty [PED free] ... and no, they didn't lose all their gains after they jumped off. 
Another individual noted: 'Not going to lie, my experience was great and my bike [PEDs] was very small and cheap (under 300 dollars). No negative sides that you hear tons about ... they really are like magic. This inference simultaneously enabled PED use and promoted the stigmatization of PED use. Specifically, individuals feared that open admittance would lead others to attribute their achievements entirely to PEDs:

Steroids are looked down on by the general public as bad as heroin and meth. People are not going to blab unnecessarily about something that is illegal, considered disgusting by John Q, and might lead others to believe their considerable achievements in fitness are now weak or mean nothing because of using.

\section{Necessity-inference}

The second inference that was hypothesized to enable PED use involved the belief that an achievement or goal could only be achieved with the use of PEDs: 'It's just annoying seeing all these dudes who clearly aren't natty [use PEDs], yet telling every delusional person [de-identified] who thinks they will ever have a decent physique false hope', while another noted: 'harsh reality but if you want to have a great physique like some of the ones posted lately, you're going to have to use gear [PEDs]'. This inference appeared to be an outcome of years of experience in bodybuilding, and functioned to enable PED use as individuals would perceive PED use as a necessary route to goal achievement: 'vitamin T [PEDs] is the only way to get huge. It took me five years of consistent lifting to find out'.

\section{Drivers}

Drivers are factors that were likely to influence individuals toward the use of PEDs. These were embedded with discrete goals and were subsequently dependent upon the individual's motives.

\section{Motivational style}

Individuals within the community typically illustrated an explicit motivational style. Some individuals demonstrated an inherent enjoyment in weightlifting: 'lifting is like breathing to me now ... I just do it, I cannot see myself not doing it', 'I never lifted for anyone but me' and 'When I started blowing off girls to go to the gym. Realized at that point it was more for me than them'. However, as expected of the online domain, these individuals were a noticeable minority that offered minimal data. Those individuals who demonstrated an external motivational style were far more prevalent and offered conceptually rich motives and insights. Specifically, validation emerged as a crucial impetus for these individuals, creatively described by one member:

It's like buying a Ferrari. Sure, you can keep it in the garage because you only bought it for yourself as a record of your accomplishments; but let's face it, hardly anyone ever does that. You buy a sports car to be seen in it.

Validation was defined as perceived social recognition for an individual's effort or achievement(s). Individuals would often exhibit validation-seeking motives with regard to a particular social group. Hence, the concept of validation was further distinguished based upon 
the source of validation, in which two prominent groups emerged: the specific bodybuilding community and the broader culture. These validation styles were not categorically discrete, but represented dimensions along the validation construct. Notably, each validation style involved distinctive drivers for PED use.

\section{Group-level validation}

Some individuals sought validation specifically from the online community through acts of perceived communal value. As per the rite of passage, this was explicitly demonstrated through a professed commitment to the bodybuilding lifestyle, in which sacrifice and commitment were not only construed as necessary for success, but were ascribed to the individual as inherently respected traits:

If you put in the effort and dedication, natty [PED free] or not, you're deserving of respect. It's not an easy lifestyle and it's a huge commitment. At some point you can't continue to progress without the extra boost [taking PEDs], and for those who want to continue to get better, they take the step. We're all brothers in iron.

As illustrated here, the rite of passage was indicative of the community as a cohesive social group, where individuals were accepted and validated as a member through a measure of their devotion. This appeared to enable self-enhancement, whereby individuals perceived themselves as superior to the broader culture based on standards of discipline, commitment and personal growth. Thus, the rite of passage enabled an identity shared by the online community. This style of validation therefore was interpreted as a desire for belonging and identification through group membership, and reflected validation at the group level.

\section{Group-level drivers}

Group-level drivers were highly contingent on group-level validation, which in turn was conditional on the rite of passage. Thus, for those seeking validation at the group level, drivers to engage in PED use were contingent on the rite of passage. This specifically related to experience in bodybuilding, which was perceived as essential for PED use to be considered acceptable: 'if you're considering tech [PEDs], at least train for 5+ years natty [PED-free] first', 'Nattys [PED-free individuals] look perfectly fine if you've got two years under your belt with proper diet and training. And no one should be considering touring [using PEDs] with less experience than that', while another noted:

I'm too young anyway so I want to wait, but I want to have a good amount of time under my belt as well. By then I'll have been training for around 7 years and ill be ready. Financially stable, training with lots of experience and time.

The individual who desired validation at the group level was likely to be deterred from PED use initially, to instead gain experience. Experience, in turn, could be construed as illustrative of commitment to the bodybuilding lifestyle. If the individual engaged in PED use prior to gaining experience, others would infer that any achievement made by the individual was the result of the PEDs (the efficacy inference), not the individual's effort or discipline. In contrast, if an individual was perceived as experienced, then they were inferred to have 'passed' the community's rite of passage. For these individuals, PED use was accepted and even considered essential: 'My goal when I started was to be 215-220 lbs at a single digit $\mathrm{BF} \%$. Wasn't going to get there natty [PED free] so I decided to take the plunge'. In this circumstance, the driver for PED use was related to the outcome of years of experience, 
specifically whether the individual perceived an expectation-discrepancy between one's effort and the expected outcome:

The amount of time, blood, sweat \& tears it takes to maintain that 'reasonable' physique is way too much. The thought of going to France [using PEDs] simply came because every lifter wonders about that country [PEDs] and all it has to offer.

This typically concerned the individual's aesthetics; a colloquial term that referred to a physique with perceived value: 'It's a hard decision not going the dark way [using PEDs] ... I just want a somewhat aesthetic physique. For these individuals, aesthetics were representative of the group characteristics that the individual wished to symbolize, as per the rite of passage. If the individual perceived their aesthetic outcome as less than equal to the effort involved, or to not meeting their internalized expectations, this could justify the use of PEDs:

It's not until you really delve deeper that you realise how difficult, if not impossible it is to achieve the above physique naturally. Pretty much ever person [de-identified] I've seen with a decent physique has admitted to not being natty [PED use] or says 'yes' when asked. Leaves you pondering what to do after 3-4 years of solid natural lifting.

The necessity inference, related to the perceived necessity of PEDs, subsequently developed from this process, and in turn further enabled PED use for those seeking validation at the group level who perceived an expectation discrepancy.

\section{Cultural-level validation}

In contrast to those individuals seeking validation through acts of perceived communal value, there were many other individuals who desired an enhanced physique due to the perceived emphasis western cultures place on appearance with regard to respect, financial success and sexual appeal: 'Everyone lifts to impress girls (or guys) to a certain degree. Anyone who says they lift (aesthetically speaking) purely for themselves is lying'. Accordingly, these individuals reflected a desire for validation at the cultural level:

When I started lifting I wanted to look like one of my mates (no homo) always thought he had a sick physique because I was such a scrawny little ${ }^{\star * * *}$ er at 16 . Started lifting just after turning 17, within 6 months I had a better body than him and now at nearly 2 years I look pretty sickening. Never been one to look in the mirror and go 'do I even lift'. I think I look good, mates tell me I'm wedge, girls I shag tell me my body's amazing - it's all good. If my viewpoint on that ever changes I'll just hop on a bicycle [use PEDs].

\section{Cultural-level drivers}

The primary goal for individuals seeking validation at the cultural level was aesthetic enhancement due to the perception that aesthetics were associated with respect and sexual appeal. For these individuals, this desire would act as a primary driver for the individual to engage in PED use:

I'm not advocating pro-roiding, but really, the only one you're cheating is yourself; you're probably never going to compete ... so you're in reality just aspiring to look good while on the beach. The sooner you realise that, the sooner you'll join the dark side [begin using PEDs].

However, this was merely the preliminary motive. The crucial incentive for these individuals was the passage of time: 'Lots of people haven't come close to reaching their natty [PED-free] 
limit and decide to juice [use PEDs] because its faster'. To achieve validation, these individuals would engage in PED use to attain their aesthetic goal in a reduced time period:

You only live 1 life guys, I'd rather get jacked and shredded in a couple years, reap the rewards and just maintain naturally [without PEDs], than having to dedicate a large part of my life trying to achieve a physique that once you get it, it'll be too late and you'll regret not teching [using PEDs]. When that happens, it's game over, you just lost at life - since you only get one life, you can't take your youth back.

Such individuals rarely exhibited a desire for validation at the group level, and thus likely placed little value in a sense of belonging to the group. By using PEDs as a short cut to their goal, they bypassed the rite of passage.

\section{Inhibitors}

For many individuals, a strong desire to engage in PED use was demonstrably repressed as a result of perceived characteristics of PED use. These inhibitors were defined as factors that were sufficient to deter individuals from PED use.

\section{Fear}

Inhibitors primarily concerned fear. Specifically, fear related to perceived health-related outcomes of PED use: 'Seeing pics like this gives me mixed feelings. Makes me want to get on the bike [use PEDs] but I never will out of fear of medical issues', while another noted: 'Nattys [PED free] live longer. There's a reason evolution doesn't have us looking like him [de-identified], it's not healthy'.

For those individuals who sought validation at the cultural-level, health-related factors were interpreted as inhibitors for aesthetic purposes. Specifically, damaging the individual's aesthetic appeal with side effects such as hair loss, 'Hair loss, this would be the worst. I'm of the opinion that bald guys can't be aesthetic (very rare)', and acne: 'Acne ... If you're trying to be aesthetic, these things will kill you which defeats the purpose of it anyways'. These attributes had perceived low-cultural value and PED use contradicted the individual's validation-seeking goal.

Sexual dysfunction was a common factor that extended from hormonal damage: 'I don't want my sex drive to take a hit which it eventually will if you decide to come off'. Another individual noted not only the perceived sexual properties, but alluded to the fear of becoming addicted to PEDs: 'the two reasons why I will never do cell-tech [PEDs], is because I'm afraid to fukk up my libido and am afraid of becoming addicted to the effects. This illustrated an additional inhibitor, specifically an implicit fear that PEDs are an addictive and easily abused substance.

Individuals perceived a slippery slope of PED use, where usage would inevitably lead to addiction. In this circumstance, the enabling inference related to the perceived effectiveness of PEDs (efficacy inference) could potentially inhibit PED use, as the perceived efficacy of PEDs enhanced the community's fear of addiction:

1-3 cycles would have little effect on you permanently ... but the saying 'nobody cycles once' doesn't exist for nothing. Talk to any guy who juices [uses PEDs] and they will say 'oh yeah I was just gonna do one or two cycles but I'm on my 8th and planning my 9th'. Like I said it's a slippery slope [emphasis added], once you have tasted the gains of juice [PEDs] it is very hard to go back to training 'naturally' again. 


\section{Statement of hypotheses}

The proposed model was elaborate and thus, the results will conclude with a statement of hypotheses. It was hypothesized that the probability of a recreational bodybuilder engaging in PED use could be determined by their validation-seeking motive. For individuals who sought validation at the group level, a rite of passage process contingent on indices of sacrifice and commitment to bodybuilding would function as a PED use deterrent, at least initially, as PED use would contradict their validation-seeking goal. If after achieving their group-validation goal, the individual perceived an expectation discrepancy, the necessity inference would enable PED use. It was also hypothesized that for those individuals who sought validation at the cultural level, the efficacy inference would enable PED use, as individuals were motivated to achieve aesthetics in a reduced timeframe. Both enabling inferences were hypothesized to share a reciprocal-cyclical relationship from the process by which they emerged (see Figure 2), and while distinctive, were notably interrelated in nature.

It was also hypothesized that, regardless of an individual's validation goal, PED use would be inhibited by fear of health-related consequences. The individual's validation style could however explain how the individual facilitated the decision to deter from PED use. An individual motivated by group validation was more likely to relate health outcomes with their health, whereas an individual motivated by cultural validation was more likely to anticipate health outcomes as a detriment to their appearance.

\section{Discussion}

The present study intended to develop a conceptual understanding of PED use amongst an online recreational bodybuilding community. Specific research aims were to develop an understanding of the motives to engage in PED use, how the relation between health outcomes and PED use are interpreted by community members, and the social processes within the online community. The developed framework integrated concepts of all research aims. The core category to emerge was social validation, defined as perceived social recognition for an individual's effort or achievement. The validation style an individual adopts was hypothesized to explain how the enabling inferences that propagated throughout the online community were developed, and how the individual would rationalize the decision to engage in PED use.

Those seeking group validation would aim to demonstrate commitment to the bodybuilding lifestyle. This was enabled by the rite of passage that facilitated group cohesiveness. Those who circumvented this process were evaluated negatively, and those who endeavoured to gain experience in bodybuilding were evaluated positively. The necessity inference developed from and enabled PED use for individuals who, after attaining group validation, perceived an expectation discrepancy. Conversely, those seeking cultural validation may engage in PED use to attain a particular physical appearance in a reduced time frame. The efficacy inference developed from and enabled PED use for these individuals.

The health outcomes were hypothesized to be evaluated negatively by the community. Specifically, fear of perceived health risks could inhibit PED use for any individual. The individual's validation style would determine how the individual likely interpreted the inhibitor; those pursuing group validation were inhibited for reasons associated with general health, and those seeking cultural validation were inhibited for reasons associated with 
appearance. Over all, these hypothesized outcomes can be interpreted within a number of theoretical frameworks.

\section{The self-concept}

Social-identity theory (Tajfel and Turner 1986) and its extension, and self-categorization theory (Turner 1985; Turner et al. 1987) offer a comprehensive conceptualization of the psychological and social processes in the current study. Turner (1975) postulated that an underlying need for a positive self-concept, one's self-definition, may be achieved through self-esteem. Self-esteem, in turn, is attained through positively perceived evaluations by others' during social interaction (Felson 1989; Marsh, Barnes, and Hocevar 1985; Miyamoto and Dornbusch 1956). The validation hypothesis in the current study suggests that perceived recognition by others may have motivational properties that enable self-bolstering. Previously, Fudala et al. (2003) and Walker and Joubert (2011) found participants engaged in PED use to enhance their perceived appearance due to an underlying need for self-esteem. Thus, it is feasible that the validation process is related to an individual's need for affirming a positive self-concept. Potentially, social validation is sought as it enhances self-esteem through perceived positive-evaluations by others.

According to self-categorization theory (Turner et al. 1987), the need for affirming the self-concept results in categorization of the self and others into social groups, specifically to establish positive distinctiveness between in-group and out-group members through social comparisons. The online community would regularly make such comparisons, such as through derogatory references to the broader culture on indices of appearance, discipline and pain endurance. Likewise, similar comparative themes emerged in the online community reported by Smith and Stewart (2012), and in real-world bodybuilding communities reported by other researchers (Andrews, Sudwell, and Sparkes 2005; Probert, Leberman, and Palmer 2007; Probert, Palmer, and Leberman 2007; Sagoe, Andreassen, and Pallesen 2014; Smith et al. 2010). Social-identity theory (Tajfel and Turner 1986) specifies that the characteristics that are used for group classification may be incorporated into one's self-concept if they are endorsed through group interaction. Speculatively, through group interaction, the traits that enabled social comparisons may have become a constituent aspect of the online group's identity. Thus, the rite of passage would enable a positive distinction between community members and the broader culture, thereby facilitating a self-concept affirmation.

This conceptualization may help unify prior research outcomes concerning the role of body-image. Similar to findings by Andrews, Sudwell, and Sparkes (2005) and Probert, Leberman, and Palmer (2007), appearance was fundamental to the online community, and was a primary method for attaining social validation. Yet, rarely did the online community exhibit pathological body-image disturbances to the extent of those reported in previous research (Blouin and Goldfield 1995; Goldfield 2009; Hallsworth, Wade, and Tiggemann 2005). If validation is interpreted as a need for affirming the self-concept, then body-image disturbances may be the result of a heightened need for self-esteem (perceived positive evaluations by others). It is feasible that seeking self-esteem through appearance measures could inevitably lead to body-image pathology that, through group interaction, instigates PED use.

Conceptualizing social validation as a need for self-concept affirmation may additionally aid in an understanding of previous findings related to the deterrent effect of moral values found for some recreational bodybuilders, despite an apparent absence of 
ethical restrictions for these athletes (Probert, Palmer, and Leberman 2007). Monaghan (2002) found that, because of perceived disapproval and legal sanctions, the bodybuilding community would engage in strategies to circumvent PED discussion, while Probert, Palmer, and Leberman (2007) reported a number of bodybuilders cited personal ethics as a primary PED use inhibitor. It is theoretically viable that moral values may inhibit PED use in these athletic communities due to the perception of PED use as immoral behaviour; the perceived negative evaluations associated with PED use would reduce the individuals' self-esteem and thus go against the need for a positive affirmation of the self-concept.

\section{Goal contents theory}

Alternatively, social validation may be conceptualized through goal contents theory (Gunnell et al. 2014). Developed within self-determination theory (Deci and Ryan 2000), goal contents theory proposes that an individual's goal may be internally oriented (intrinsic) or externally oriented (extrinsic). Extrinsic goals are characterized by an emphasis on external indicators of value, including social recognition, and an individual's image or attractiveness (Deci and Ryan 2000). Indeed, validation was heavily reliant on appearance within the online community of the current study and in previous work (Smith and Stewart 2012). If this interpretation is accurate, then this may suggest an association between doping and extrinsic motivation, and thus provide partial support for Donahue et al. (2006) motivational model. Research could assess for the relation between both constructs by measuring validation styles for similar outcomes to those empirically related to extrinsic goals, including poor well-being (Sebire, Standage, and Vansteenkiste 2009) and reduced exercise performance (Vansteenkiste et al. 2004).

\section{Moral disengagement}

An alternative conceptualization of the social comparison process is through moral disengagement (Bandura et al. 1996), specifically the advantageous comparison mechanism, in which the perceived harm of an action is minimized by drawing comparisons between it and other reprehensible behaviour. Similar to Monaghan (2002), the online community would selectively relate themselves to the broader culture on a number of health-related indices, a process similarly found in Boardley and Grix's (2014) qualitative interviews investigating moral disengagement. The selective use of language during discussion of PEDs could also be conceptualized as support for the euphemistic labelling mechanism (Bandura et al. 1996). However, the selective language in the current study can likely be attributed to the moderating sanctions limiting direct discussion of PEDs within the online community. Moreover, there were no explicit indications of diffusion of responsibility or displacement of responsibility, which Boardley and Grix (2014) postulated were innate instigators of PED use. Subsequently, a comprehensive understanding of the present study cannot be achieved through moral disengagement, and as a consequence, results provide minimal support for Bandura et al.s (1996) moral disengagement mechanisms.

Indeed, the present study generally found minimal association between PED use and individual moral values. While theoretical sampling (Strauss 1987) may have biased data collection, coding was rigorous, rather than selective (Kozinets 2010). However, temporal 
constraints and the sheer amount of traffic on the chosen research site were restrictive, and data related to moral values may have been omitted. The present study nevertheless provides some support that the role of moral values (Barkoukis et al. 2011, 2013; Lazuras et al. 2010) may be insignificant to non-competitive athletes.

\section{Strengths}

Given the trend of quantitative survey-based doping research, the strengths of the present study are in its unique contributions to the doping literature, both at a theoretical and methodological level.

\section{A preliminary health-framework}

The hypothesized fear-inhibiting factors are important findings that contribute to the existing literature. Previous research is minimal on all three accounts. Probert, Leberman, and Palmer (2007) found that some bodybuilders chose against PED use for its purported negative health consequences, while Christiansen and Bojsen-Møller (2012) reported that, through an online-counselling-for-doping web page, young adult males illustrated fear of sexual ramifications from doping. This sequence is logical given that many of the reported health risks of doping are associated with hormonal and sexual functioning (Amsterdam, Opperhuizen, and Hartgens 2010). The current study substantiates and unifies these findings into a preliminary framework.

The fear-inhibiting factor related to PED addiction was an unforeseen result. While Keane (2005) and McDuff and Baron (2005) have proposed abuse and addiction models of doping in bodybuilding, there was little evidence of either in the online community. Rather, it appeared that the normative inference related to the perceived efficacy of PEDs facilitated the community's fear of addiction. These findings are not suggestive of an addiction model of doping, rather they illustrate that the anticipated efficacy of PEDs may act as a deterrent for recreational bodybuilders. While previous research has emphasized the role of efficacy beliefs concerning resistance to social pressure (Lucidi et al. 2004, 2008), the present study suggests that efficacy beliefs directly related to doping substances may both enable and inhibit doping in recreational bodybuilders. This is a unique contribution to the existing literature, and future researchers should investigate this process further in similar populations.

\section{Social desirability}

The innovative research design has provided a methodology which is, presumably, not limited by concerns of social desirability. Monaghan (2002) claimed that social desirability would ultimately limit the capacity for a conceptual understanding of doping in recreational bodybuilders. Yet, similar to Smith and Stewart (2012), the present study made a number of in-depth accounts of PED-related discussions, while circumventing the potentially difficult process of gaining the trust of the community such as was reported by Andrews, Sudwell, and Sparkes (2005). While no discrete measure of social desirability was applied, the observational nature of research provides support that social desirability was negligible (Mays and Pope 1995). Subsequently, a major strength of the present research is its showcasing of 
the online research approach as a gateway for researchers to potentially bypass the social desirability concern apparent within survey-based doping research (Alaranta et al. 2006; Kisaalita and Robinson 2014; Lazuras et al. 2010).

\section{Limitations}

Due to the anonymity of online communication, findings cannot be generalized. Specifically, while the online community was seemingly comprised recreational bodybuilding athletes, no demographic information can be reliably inferred. Nonetheless, given the constructivist approach adopted (Lincoln and Guba 2000), the purpose was not to infer generalizability, but rather to generate hypotheses in a research area where conceptual growth is absent. The present study thus lays a plausible foundation for future theoretical developments. To our knowledge, there has been no doping research within a framework of social-identity theory (Tajfel and Turner 1986) and self-categorization theory (Turner et al. 1987). While speculative, the pressing issues concerning the quality of existing research (Backhouse et al. 2007) indicate that applying well-established theory may facilitate higher standards in future research.

Nevertheless, future research should seek out ways of enhancing validity and generalizability. A provisional method may be through member checking (Simon 2011), a procedure by which feedback from participants is sought for information verification. Due to the anonymity of the online community, the capacity for a reliable member check was restricted. This procedure could have minimized any subjectivity bias that affected data analysis. Indeed, in adopting a constructivist stance (Lincoln and Guba 2000), it must be acknowledged that the researcher's biases had an innate impact on the data analytic process. To minimize bias, future research could apply triangulation (Golafshani 2003), the use of multiple measures to substantiate a hypothesis (Creswell and Miller 2000). Investigator triangulation (Johnson 1997) was attained in the present study through the use of an independent coder. This was considered sufficient, as given the preliminary nature of research, an additional (and hence resource-consuming) measure was considered preemptive. Future research could adopt a mixed-method triangulation approach, as this could facilitate the strengths of both qualitative and quantitative methodologies.

\section{Implications and conclusion}

Recognizing that fear of health risks may act to deter recreational athletes from doping may have implications for anti-doping policy. Intervention strategies could, for example, enhance the salience of detrimental appearance outcomes (e.g. acne and balding) as the present study supports that, for some, doping is primarily driven by appearance. Yet, given the legitimacy of the health risks associated with anabolic steroids - the doping substances most commonly used amongst the general public (Simon et al. 2006) - and an estimated prevalence of between one and three million in the USA alone (Sjöqvist, Garle, and Rane 2008), there remains a need in understanding why health risks fail to deter all athletes. It has been noted elsewhere that a widespread mistrust toward the medical community has been held by both competitive and non-competitive athletes for some time (Dawson 2001). Further, Monaghan (2002) demonstrated a commonly held belief among community athletes that doping was not 'unhealthy', and that health risks are typically exaggerated in 
layperson contexts. Future research should consider the possibility that some may doubt the existence or relevance of health risks, and could explore methods for increasing trust toward the medical community.

At present, doping research remains in disarray. It is the responsibility of researchers to now deviate from ethically framed research within elite-athletic populations and converge upon theory-driven risk-prevention research. The present study has illustrated a glimpse at the world of doping in recreational bodybuilding, one that self-instigates doping through the desire for social validation. Doping is likely to continue to proliferate in recreational athletic communities for as long as researchers fail to address both the lack of rigorous theoretical developments, and the methodological issues related to social desirability. The result will have far reaching consequences, not only for the longevity of athletic sporting careers, but for the health and safety of recreational athletes throughout sporting cultures everywhere.

\section{Disclosure statement}

No potential conflict of interest was reported by the authors.

\section{References}

Alaranta, A., H. Alaranta, J. Holmila, P. Palmu, K. Pietilä, and I. Helenius. 2006. "Self-reported Attitudes of Elite Athletes towards Doping: Differences between Type of Sport." International Journal of Sports Medicine 27 (10): 842-846. doi:10.1055/s-2005-872969.

American Psychological Association. 2010. Publication Manual of the American Psychological Association. 6th ed. Washington, DC: American Psychological Association.

Amsterdam, J. V., A. Opperhuizen, and F. Hartgens. 2010. "Adverse Health Effects of Anabolicandrogenic Steroids." Regulatory Toxicology and Pharmacology 57 (1): 117-123. doi:10.1016/j. yrtph.2010.02.001.

Andrews, G. J., M. I. Sudwell, and A. C. Sparkes. 2005. "Towards a Geography of Fitness: An Ethnographic Case Study of the Gym in British Bodybuilding Culture." Social Science and Medicine 60 (4): 877-891. doi:10.1016/j.socscimed.2004.06.029.

Backhouse, S. H., J. McKenna, S. Robinson, and A. Atkin. 2007. Attitudes, Behaviours, Knowledge and Education - Drugs in Sport: Past, Present, and Future, 1-199. World Anti-Doping Agency. https://www.wada-ama.org.

Bandura, A., C. Barbaranelli, G. V. Caprara, and C. Pastorelli. 1996. "Mechanisms of Moral Disengagement in the Exercise of Moral Agency." Journal of Personality and Social Psychology 71 (2): 364-374. http://www.apa.org/pubs/journals/psp.

Barkoukis, V., L. Lazuras, and H. Tsorbatzoudis. 2013. "Beliefs about the Causes of Success in Sports and Susceptibility for Doping Use in Adolescent Athletes." Journal of Sports Sciences 32 (3): 212-219. doi:10.1080/02640414.2013.819521.

Barkoukis, V., L. Lazuras, H. Tsorbatzoudis, and A. Rodafinos. 2011. "Motivational and Sportspersonship Profiles of Elite Athletes in Relation to Doping Behavior." Psychology of Sport and Exercise 12 (3): 205-212. doi:10.1016/j.psychsport.2010.10.003.

Barkoukis, V., L. Lazuras, H. Tsorbatzoudis, and A. Rodafinos. 2013. "Motivational and Social Cognitive Predictors of Doping Intentions in Elite Sports: An Integrated Approach." Scandinavian Journal of Medicine and Science in Sports 23 (5): 330-340. doi:10.1111/sms.12068.

Bilard, J. 2011. "Motives for Illicit Use of Doping Substances among Athletes Calling a National Antidoping Phone-help Service: An Exploratory Study." Substance Use \& Misuse 46 (4): 359-367. doi: $10.3109 / 10826084.2010 .502553$.

Birks, M., and J. Mills. 2011. Grounded Theory: A Practical Guide. Thousand Oaks, CA: Sage.

Blouin, A. G., and G. S. Goldfield. 1995. "Body Image and Steroid Use in Male Bodybuilders." International Journal of Eating Disorders 18 (2): 159-165. http://onlinelibrary.wiley.com/ journal/10.1002/(ISSN)1098-108X. 
Boardley, I. D., and J. Grix. 2014. "Doping in Bodybuilders: A Qualitative Investigation of Facilitative Psychosocial Processes." Qualitative Research in Sport, Exercise and Health 6: 37-41. doi:10.1080 /2159676X.2013.766809.

Christiansen, A. V., and J. Bojsen-Møller. 2012. “Will Steroids Kill Me If I Use Them Once?' A Qualitative Analysis of Inquiries Submitted to the Danish Anti-doping Authorities." Performance Enhancement and Health 1 (1): 39-47. doi:10.1016/j.peh.2012.05.002.

Creswell, J. W., and D. L. Miller. 2000. "Determining Validity in Qualitative Inquiry." Theory into Practice 39 (3): 1-130. http://www.tandfonline.com/loi/htip20\#.VDeRM_mSySo.

Dawson, R. T. 2001. "Drugs in Sport - The Role of the Physician." Journal of Endocrinology 170: 55-61. doi:10.1677/joe.0.1700055.

Deci, E. L., and R. M. Ryan. 2000. "The 'What' and 'Why' of Goal Pursuits: Human Needs and the Self-determination of Behavior." Psychological Inquiry 11 (4): 227-268. doi:10.1207/ s15327965pli1104_01.

Denscombe, M. 2010. The Good Research Guide: For Small-scale Research Projects. 4th ed. Maidenhead: Open University Press.

Diehl, K., A. Thiel, S. Zipfel, Mayer, J., D. G. Litaker, and S. Schneider. 2012. "How Healthy is the Behavior of Young Athletes? A Systematic Literature Review and Meta-analyses." Journal of Sports Science and Medicine 11 (2): 201-220. http://www.jssm.org.

Donahue, E. G., P. Miquelon, P. Valois, C. Goulet, A. Buist, and R. J. Vallerand. 2006. "A Motivational Model of Performance-enhancing Substance Use in Elite Athletes." Journal of Sport and Exercise Psychology 28 (4): 511-520. http://journals.humankinetics.com/JSEP.

Donovan, R. J., G. Egger, V. Kapernick, and J. Mendoza. 2002. "A Conceptual Framework for Achieving Performance Enhancing Drug Compliance in Sport." Sports Medicine 32 (4): 269-284. http://sma.org.au.

Ehrnborg, C., and T. Rosén. 2009. "The Psychology behind Doping in Sport." Growth Hormone and IGF Research 19 (4): 285-287. doi:10.1016/j.ghir.2009.04.003.

Engelberg, T., S. Moston, and J. Skinner. 2012. "Public Perception of Sport Anti-doping Policy in Australia." Drugs: Education, Prevention and Policy 19 (1): 84-87. doi:10.3109/09687637.2011.5 90556

Felson, R. B. 1989. “Parents and the Reflected Appraisal Process: A Longitudinal Analysis.” Journal of Personality and Social Psychology 56: 965-971.

Fudala, P. J., R. M. Weinrieb, J. S. Calarco, K. M. Kampman, and C. Boardman. 2003. "An Evaluation of Anabolic-androgenic Steroid Abusers over a Period of 1 Year: Seven Case Studies." Annals of Clinical Psychiatry 15 (2): 121-130. https://www.aacp.com.

Gennep, A. V. 1960. The Rites of Passage. Chicago: University of Chicago Press.

Golafshani, N. 2003. "Understanding Reliability and Validity in Qualitative Research.” The Qualitative Report 8 (4): 597-607. https://www.nova.edu/sss/QR.

Goldfield, G. S. 2009. "Body Image, Disordered Eating and Anabolic Steroid Use in Female Bodybuilders." Eating Disorders 17: 200-210. doi:10.1080/10640260902848485.

Guba, E., and Y. Lincoln. 1989. Fourth Generation Evaluation. Newbury Park, CA: Sage.

Gucciardi, D. F., G. Jalleh, and R. J. Donovan. 2011. "An Examination of the Sport Drug Control Model with Elite Australian Athletes." Journal of Science and Medicine in Sport 14 (6): 469-476. doi:10.1016/j.jsams.2011.03.009.

Gunnell, K. E., P. R. E. Crocker, D. E. Mack, P. M. Wilson, and B. D. Zumbo. 2014. "Goal Contents, Motivation, Psychological Need Satisfaction, Well-being and Physical Activity: A Test of Selfdetermination Theory over 6 Months." Psychology of Sport \& Exercise 15 (1): 19-29. doi:10.1016/j. psychsport.2013.08.005.

Hallsworth, L., T. Wade, and M. Tiggemann. 2005. "Individual Differences in Male Body-image: An Examination of Self-objectification in Recreational Body Builders." British Journal of Health Psychology 10 (3): 453-465. doi:10.1348/135910705X26966.

Hauw, D., and M. McNamee. 2015. "A Critical Analysis of Three Psychological Research Programs of Doping Behaviour." Psychology of Sport and Exercise 16 (2): 140-148. doi: 10.1016/j. psychsport.2014.03.010. 
Hodge, K., E. A. Hargreaves, D. Gerrard, and C. Lonsdale. 2013. "Psychological Mechanisms Underlying Doping Attitudes in Sport: Motivation and Moral Disengagement." Journal of Sport and Exercise Psychology 35 (4): 419-432. http://journals.humankinetics.com/JSEP.

Holt, R. I. G., I. Erotokritou-Mulligan, and P. H. Sönksen. 2009. “The History of Doping and Growth Hormone Abuse in Sport." Growth Hormone \& IGF Research 19: 320-326. doi:10.1016/j. ghir.2009.04.009.

Jalleh, G., R. J. Donovan, and I. Jobling. 2014. "Predicting Attitude towards Performance Enhancing Substance Use: A Comprehensive Test of the Sport Drug Control Model with Elite Australian Athletes." Journal of Science and Medicine in Sport 17 (6): 574-579. doi: 10.1016/j.jsams.2013.10.249.

Johnson, R. B. 1997. "Examining the Validity Structure of Qualitative Research." Education 118 (2): 282-292.

Kanayama, G., J. I. Hudson, and H. G. Pope Jr. 2008. "Long-term Psychiatric and Medical Consequences of Anabolic-androgenic Steroid Abuse: A Looming Public Health Concern?” Drug and Alcohol Dependence 98: 1-12. doi:10.1016/j.drugalcdep.2008.05.004.

Kayser, B., A. Mauron, and A. Miah. 2007. “Current Anti-doping Policy: A Critical Appraisal.” BMC Medican Ethics 8 (2): doi:10.1186/1472-6939-8-2.

Keane, H. 2005. "Diagnosing the Male Steroid User: Drug Use, Body Image and Disordered Masculinity." Health 9 (2): 189-208. doi:10.1177/1363459305050585.

Kisaalita, N. R., and M. E. Robinson. 2014. "Attitudes and Motivations of Competitive Cyclists regarding Use of Banned and Legal Performance Enhancers." Journal of Sports Science and Medicine 13 (1): 44-50. http://www.jssm.org.

Kozinets, R. V. 2010. Netnography. Doing Ethnographic Research Online. Thousand Oaks, CA: Sage.

Lazuras, L., V. Barkoukis, A. Rodafinos, and H. Tzorbatzoudis. 2010. "Predictors of Doping Intentions in Elite-level Athletes: A Social Cognition Approach." Journal of Sport \& Exercise Psychology 32: 694-710. http://journals.humankinetics.com/JSEP.

Lincoln, Y. S., and E. S. Guba. 2000. "Paradigmatic Controversies, Contradictions, and Emerging Confluences." In The Hanbook of Qualitative Research, edited by K. Norman, D. Lincoln, and Y. S. Lincoln, 163-188. London: Sage.

Lipinski, T. A. 2006. "Emerging Tort Issues in the Collection and Dissemination of Internet-based Research Data." Journal of Information Ethics 15 (2): 55-81. doi:10.3172/JIE.15.2.55.

Lucidi, F., C. Grano, L. Leone, C. Lombardo, and C. Pesce. 2004. "Determinants of the Intention to Use Doping Substances: An Empirical Contribution in a Sample of Italian Adolescents." International Journal of Sport Psychology 35 (2): 133-148. http://www.ijsp-online.com.

Lucidi, F., A. Zelli, and L. Mallia. 2013. "The Contribution of Moral Disengagement to Adolescents Use of Doping Substances." International Journal of Sport Psychology 44 (6): 493-514. doi:10.7352/ IJSP2013.44.493.

Lucidi, F., A. Zelli, L. Mallia, C. Grano, P. M. Russo, and C. Violani. 2008. “The Social-cognitive Mechanisms Regulating Adolescents' Use of Doping Substances.” Journal of Sports Sciences 26 (5): 447-456. doi:10.1080/02640410701579370.

Markham, A. 2004a. "Internet as Research Context." In Qualitative Research Practice, edited by C. Seale, J. Gubrium, and D. Silverman, 358-374. London: Sage.

Markham, A. 2004b. "Internet Communication as a Tool for Qualitative Research." In Qualitative Research: Theory, Method, and Practices. 2nd ed., edited by D. Silverman, 95-124. London: Sage.

Marsh, H. W., J. Barnes, and D. Hocevar. 1985. "Self-other Agreement on Multidimensional Selfconcept Ratings: Factor Analysis and Multitrait-multimethod Analysis." Journal of Personality and Social Psychology 49: 1360-1377.

Maykut, P., and R. Morehouse. 1994. Beginning Qualitative Research: A Philosophical and Practical Guide. Washington, DC: Falmer Press.

Mays, N., and C. Pope. 1995. "Qualitative Research: Observational Methods in Health Care Settings." British Medical Journal 311 (6998): 182-184. doi:10.1136/bmj.311.6998.182.

McDuff, D. R., and D. Baron. 2005. "Substance Use in Athletics: A Sports Psychiatry Perspective." Clinics in Sports Medicine 24 (4): 885-897. doi:10.1016/j.csm.2005.06.004.

Mills, J., A. Bonner, and K. Francis. 2006. “The Development of Constructivist Grounded Theory." International Journal of Qualitative Methods 5 (1): 1-10. http://www.ualberta.ca/ iiqm. 
Miyamoto, S. F., and S. Dornbush. 1956. "A Test of Interactionist Hypotheses of Self-conception." American Journal of Sociology 61: 399-403.

Monaghan, L. F. 2002. "Vocabularies of Motive for Illicit Steroid Use among Bodybuilders." Social Science \& Medicine 55: 695-708. doi:10.1016/S0277-9536(01)00195-2.

Morente-Sánchez, J., and M. Zabala. 2013. "Doping in Sport: A Review of Elite Athletes' Attitudes, Beliefs, and Knowledge." Sports Medicine 43 (6): 395-411. doi:10.1007/s40279-013-0037-x.

Moston, S., T. Engelberg, and J. Skinner. 2014. "Athletes' and Coaches' Perceptions of Deterrents to Performance-enhancing Drug Use." International Journal of Sport Policy and Politics. doi:10.108 $0 / 19406940.2014 .936960$.

Pedersen, I. G. 2010. "Doping and the Perfect Body Expert: Social and Cultural Indicators of Performance-enhancing Drug Use in Danish Gyms." Sport in Society 13 (3): 503-516. doi:10.1080/17430431003588184.

Petróczi, A. 2007. "Attitudes and Doping: A Structural Equation Analysis of the Relationship between Athletes' Attitudes, Sport Orientation and Doping Behaviour." Substance Abuse Treatment, Prevention, and Policy 2 (34): 34-48. doi:10.1186/1747-597X-2-34.

Petróczi, A., and E. Aidman. 2009. "Measuring Explicit Attitude toward Doping: Review of the Psychometric Properties of the Performance Enhancement Attitude Scale." Psychology of Sport and Exercise 10 (3): 390-396. doi:10.1016/j.psychsport.2008.11.001.

Probert, A., S. Leberman, and F. Palmer. 2007. "New Zealand Bodybuilder Identities: Beyond Homogeneity." International Review for the Sociology of Sport 42 (1): 5-26. doi:10.1177/1012690207081921.

Probert, A., F. Palmer, and S. Leberman. 2007. “The Fine Line: An Insight into 'Risky' Practices of Male and Female Competitive Bodybuilders." Annals of Leisure Research 10 (3-4): 272-290. doi: 10.1080/11745398.2007.9686767.

QSR International. 2012. Nvivo 10 [Computer Software]. http://www.qsrinternational.com.

Sagoe, D., and C. S. Andreassen. 2014. "The Global Epidemiology of Anabolic-androgenic Steroid Use: A Meta-analysis and Meta-regression Analysis.” Annals of Epidemiology 24(5): 383-398. doi:10.1016/j.annepidem.2014.01.009.

Sagoe, D., C. S. Andreassen, and S. Pallesen. 2014. "The Aetiology and Trajectory of Anabolicandrogenic Steroid Use Initiation: A Systematic Review and Synthesis of Qualitative Research.” Substance Abuse: Treatment, Prevention, and Policy 9 (1): 27-40. doi: 10.1186/1747-597X-9-27.

Sebire, S. J., M. Standage, and M. Vansteenkiste. 2009. "Examining Intrinsic versus Extrinsic Exercise Goals: Cognitive, Affective, and Behavioral Outcomes." Journal of Sport \& Exercise Psychology 31 (2): 189-210. http://journals.humankinetics.com/JSEP.

Silverman, D. 2009. Doing Qualitative Research. 3rd ed. London: Sage.

Simon, M. K. 2011. Dissertation and Scholarly Research: Recipes for Success. 2011 ed. Seattle, WA: Dissertation Success, LLC. http://dissertationrecipes.com.

Simon, P., H. Striegel, F. Aust, K. Dietz, and R. Ulrich. 2006. "Doping in Fitness Sports: Estimated Number of Unreported Cases and Individual Probability of Doping." Addiction 101 (11): 16401644. doi:10.1111/j.1360-0443.2006.01568.x.

Sjöqvist, F., M. Garle, and A. Rane. 2008. "Use of Doping Agents, Particularly Anabolic Steroids, in Sports and Society." The Lancet 371 (9627): 1872-1882. http://www.thelancet.com.

Smith, A., and B. Stewart. 2012. "Body Perceptions and Health Behaviors in an Online Bodybuilding Community." Qualitative Health Research 22 (7): 971-985. doi:10.1177/1049732312443425.

Smith, A. C., B. Stewart, S. Oliver-Bennetts, S. McDonald, L. Ingerson, A. Anderson, G. F. Dickson, P. Emery, and F. Graetz. 2010. "Contextual Influences and Athlete Attitudes to Drugs in Sport." Sport Management Review 13 (3): 181-197. doi:10.1016/j.smr.2010.01.008.

Stamm, H., M. Lamprecht, M. Kamber, B. Marti, and N. Mahler. 2008. “The Public Perception of Doping in Sport in Switzerland, 1995-2004." Journal of Sports Sciences 26 (3): 235-242. doi:10.1080/02640410701552914.

Strauss, A. L. 1987. Qualitative Analysis for Social Scientists. New York: University of Cambridge.

Strauss, A., and J. Corbin. 1998. Basics of Qualitative Research: Techniques and Procedures for Developing Grounded Theory. 2nd ed. Thousand Oaks, CA: Sage. 
Tajfel, H., and J. C. Turner. 1986. “The Social Identity Theory of Intergroup Behavior.” In The Psychology of Intergroup Relations, edited by S. Worchel and W. G. Austin, 7-24. Chicago, IL: Nelson-Hall.

Turner, J. C. 1975. "Social Comparison and Social Identity: Some Prospects for Intergroup Behaviour." European Journal of Social Psychology 5: 5-34.

Turner, J. C. 1985. "Social categorization and the Self-concept: A Social Cognitive Theory of Group Behavior." In Advances in Group Processes: Theory and research, edited by E. J. Lawler, vol. 2, 77-122. Greenwich, CT: JAI Press.

Turner, J. C., M. A. Hogg, P. J. Oakes, S. D. Reicher, and M. S. Wetherell. 1987. Rediscovering the Social Group: A Self-categorization Theory. Oxford: Blackwell.

Vansteenkiste, M., J. Simons, B. Soenens, and W. Lens. 2004. "How to Become a Persevering Exerciser? Providing a Clear, Future Intrinsic Goal in an Autonomy-supportive Way." Journal of Sport \& Exercise Psychology 26 (2): 232-249.

Verroken, M. 2000. "Drug Use and Abuse in Sport." Bailliere's Clinical Endocrinology and Metabolism 14 (1): 1-23. doi:10.1053/beem.2000.0050.

WADA. 2013. World Anti-doping Code 2015. Montreal: WADA. http://www.wada-ama.org/.

Walker, D. M., and H. E. Joubert. 2011. "Attitudes of Injecting Male Anabolic Androgenic Steroid Users to Media Influence, Health Messages and Gender Constructs." Drugs and Alcohol Today 11 (2): 56-70. doi:10.1108/17459261111174019.

Wiefferink, C. H., S. B. Detmar, B. Coumans, T. Vogels, and T. G. W. Paulussen. 2008. "Social Psychological Determinants of the Use of Performance-enhancing Drugs by Gym Users." Health Education Research 23 (1): 70-80. doi:10.1093/her/cym004.

Zelli, A., L. Mallia, and F. Lucidi. 2010. "The Contribution of Interpersonal Appraisals to a Socialcognitive Analysis of Adolescents' Doping Use." Psychology of Sport and Exercise 11 (4): 304-311. doi:10.1016/j.psychsport.2010.02.008. 